\title{
THE BALKAN COUNTRIES IN GLOBAL BURDEN OF DISEASES STUDIES
}

\author{
Dima K. TSANOVA ${ }^{1 凶}$ \\ ${ }^{1}$ Department of „Public Health Sciences“, Faculty of Public Health, Medical University-Pleven, Bulgaria \\ Received 02 Nov 2020, Accepted 21 Nov 2020 \\ https://doi.org/10.31688/ABMU.2020.55.4.16
}

\begin{abstract}
Global burden of diseases studies collected and analysed data from more than 195 countries, reflecting premature death and disability related to more than 350 diseases and injuries, by age and sex, since 1990 to the present. The national profile of each country in the studies contains comparative data for 2007 and 2019. The purpose of this paper was to analyse the differences in leading risk factors and causes of global burden of diseases between Balkan countries. The leading causes of years of life lost due to disability are mainly chronic non-communicable diseases, with the leading positions being low back pain, falls, headaches, diabetes, etc. The summary indicator for lost years of life due to premature death and disability-adjusted life years (DALYs) for 2017 again shows the leading role of ischemic heart disease and stroke. Preventable mortality in Bulgaria remains very high. Much of the overall burden of disease in Bulgaria can be attributed to behavioural risk factors, including smoking, alcohol consumption, dietary risks and low physical activity.
\end{abstract}

Keywords: global burden of diseases, Balkans, years of live lost.

\section{Abbreviations}

DALYs - Disability-adjusted life years

\section{Résumé}

Les pays des Balkans dans les études sur le fardeau global des maladies

La charge mondiale de morbidité est évaluée à partir de données de plus de 195 pays, reflétant l'incapacité et la mortalité prématurée liées à plus de 350 maladies et traumatismes, par âge et par sexe, depuis 1990 jusqu'à présent. Le profil de chaque pays dans les études contient des données comparatives pour 2007 et 2019. Le but de cette étude est d'analyser les différences entre les principaux facteurs de risque et les causes de la charge mondiale de morbidité entre les pays des Balkans. Les principales causes des années de vie perdues en raison de l'incapacité sont principalement les maladies chroniques non transmissibles, les principales positions étant détenues par les lombalgies, les chutes, les maux de tête, le diabète, etc. Les années de vie corrigées de l'incapacité pour 2017 montrent le rôle de premier plan des cardiopathies ischémiques et des accidents vasculaires cérébraux. La mortalité prématurée en Bulgarie reste très élevée. Une grande partie de la charge de morbidité globale en Bulgarie peut être attribuée à des facteurs de risque comportementaux, notamment le tabagisme, la consommation d'alcool, les risques alimentaires et une faible activité physique. $\bowtie$ Address for correspondence:
Dima K. TSANOVA

Department of „Public Health Sciences“, Faculty of Public Health, Medical University-Pleven, Bulgaria

Address: Sv. Kliment Ohridski Str.no.1, 5800 Pleven, Bulgaria

Email: d_krumova@abv.bg; Phone: +35964884278 
GBD - Global Burden of Diseases

HAQ - Healthcare Access and Quality

IM - infant mortality rate

IHME - Health Metrics and Evaluation

LE - life expectancy

SDI - Socio-Demographic Index

SDGs - Sustainable Development Goals

U5MR - under 5-mortality rate

WHO - World Health Organisation

YLLs - years of life lost

YLDs - years lived with disability

\section{INTRODUCTION}

The pursuit of a longer life is no longer enough for modern society, today the greater goal is to live longer in good health, and this is the right of all the people in the world, regardless of which country they live in. To achieve this goal, we need a comprehensive picture of what invalidates and kills people in different countries, at different times, at different ages, and in both sexes ${ }^{1,2}$. The Global Burden of Diseases (GBD) studies provide a tool for quantifying the loss of health due to hundreds of diseases, injuries and risk factors ${ }^{3}$. Survey data are particularly valuable for national health systems so that they can be improved and health inequalities eliminated. The studies collected and analysed information on more than 195 countries, reflecting premature death and disability from more than 350 diseases and injuries, by age and sex, from 1990 to the present, allowing comparisons over time, both between age groups and between different countries ${ }^{4}$. GBD health conditions are divided into three categories:

- group 1 - infectious diseases, maternal and perinatal conditions and eating disorders;

- group 2 - non-communicable diseases;

- group 3 - injuries and injuries (traffic accidents, falls, self-injuries and violence).

The first GBD study covered eight regions and five age groups and dates back to the early 1990s, when the World Bank initiated the study and included it in the 1993 World Development Report: Investing in Health ${ }^{5,6}$. This study represents the most comprehensive effort to measure systematically global health problems, generating predictions for 107 diseases and 483 consequences (non-fatal disease-related health consequences). The GBD 1990 study had a profound impact on health policy and health strategies worldwide, especially after addressing otherwise hidden or neglected health challenges, such as mental illness and the severity of road injuries.

In 1998, the World Health Organization (WHO) established the Disease Severity Unit, which
Mots-clés: charge mondiale de morbidité, mortalité prématurée, pays des Balkans, facteurs de risque.

generated estimates for 2000, 2001 and 2002, publishing the forecasts in the WHO annual health reports. In 2008, the WHO updated the forecasts for 2004. At the time of the GBD 2004 study, the causes of death and injury under investigation were 136 .

The next comprehensive study of the global burden of disease, injury and risk factors is from 2010 (GBD 2010). While mainly researchers from Harvard and the World Health Organization conducted the early studies, this study brought together a community of nearly 500 experts from around the world in epidemiology, statistics and other disciplines, supported by the Bill and Melinda Gates Foundation. It significantly expands the scope of previous research, using improved methods to assess the severity of disease. GBD 2010 prepares assessments for 291 diseases and injuries, 67 risk factors, 1160 consequences, 21 regions, 20 age groups and 187 countries $^{7,8}$.

With the Institute for Health Metrics and Evaluation (IHME) at the University of Washington, GBD 2013 expands the methodology, datasets and tools used in GBD 2010 and presents forecasts for more than 300 diseases and injuries, 79 risk factor and over 2300 consequences for 188 countries $^{3,7}$.

The preparation of annual GBD updates began in 2015. These more frequent updates provide politicians with the most timely and useful picture of health status of the population. The 2015 update expands the methodology, datasets and tools used in GBD 2013 and introduces the Socio-Demographic Index (SDI), a summary measure that identifies where countries are in the development spectrum. Expressed on a scale of 0 to 1 , the index is a composite average for the per capita income ranking, education and fertility rate of all areas in the GBD study. Forecasts have been made for 315 diseases and injuries and 79 risk factors for 195 countries $^{9-11}$.

The 2016 study includes 333 diseases and injuries, 84 risk factors, 23 age groups, calculated for 774 places. The study identifies number of health issues, including alcohol-related deaths and injuries, the 
burden of the disease in the United States, and global mortality from firearms ${ }^{3,10}$.

The 2017 study was published in November 2018. It provides for the first time an independent assessment of the world population and the population of 195 countries and territories, using a standardized, reproducible approach, as well as a comprehensive fertility analysis. Estimates of mortality and life expectancy have been extended back to 1950 , and new causes of a total of 359 diseases and injuries have been added to the list of fatal and non-fatal causes. A new risk factor has been added - "bullying victimization" and 80 new risk-outcome pairs. More indicators for the Sustainable Development Goals (SDGs) are now being explored and forecasting methods are being used to generate forecasts by 2030 and to assess the pace of change needed to achieve the SDGs ${ }^{3,12}$.

The latest study is 2019, the most comprehensive global study-analysing 286 causes of death, 369 diseases and injuries, and 87 risk factors in 204 countries and territories-reveals how well the world's population was prepared in terms of underlying health for the impact of the COVID-19 pandemic ${ }^{13}$.

The Country Profiles in GBD provide an overview of findings from the GBD. They are based on over 80,000 different data sources used by researchers to produce the most scientifically rigorous estimates possible. The country profiles in studies contain comparative data for 1990 and 20195,14.

The Balkan countries are several countries, which are entirely within the Balkan Peninsula: Albania, Bosnia and Herzegovina, Bulgaria, Montenegro, Republic of North Macedonia and those which are mostly or partially within the Balkan Peninsula: Croatia, Greece, Romania, Serbia, Slovenia, Turkey. The territory of Italy on Balkan Peninsula is only $200 \mathrm{~km}^{2}$ and we will not include it in this study. Five of Balkan countries are in the group of developed economies - Bulgaria, Greece, Croatia, Slovenia and Romania. Other five have economies in transition - Albania, Bosnia and Herzegovina, Montenegro, Republic of North Macedonia and Serbia and only Turkey is in developing economies ${ }^{15}$.

The AIM OF THE STUDY was to analyse and compare the burden of diseases and leading risk factors between Balkan countries.

\section{Material AND Methods}

For the purposes of the study, a content analysis of published data from the GBD studies for the period 1990-2019 was done.
Countries' profiles in GBD studies include the following indicators:

- Life expectancy (LE);

- Under 5 mortality rate (U5MR);

- Infant mortality rate (IM);

- Causes of death - the main cause of death, usually expressed as a proportion (per 100,000 population);

- Years of life lost (YLLs) - years of life lost to premature death;

- Years lived with disability (YLDs) - a standardized indicator for calculating years lived with disability after injury;

- Disability-adjusted life years (DALYs) - this is the sum of YLLs and YLDs, so the indicator takes into account both premature death and disability to express the total years of life lost for all reasons;

- Risk factors - any modifiable aspect of behaviour or lifestyle, as well as environmental exposures and biological characteristics that increase the likelihood of experiencing a negative health event.

The data processing was performed with a software product for statistical processing IBM SPSS v.24. The Pearson coefficient was used to establish a correlation.

The data and trends are presented in appropriate tables and are graphically illustrated.

\section{Results AND Discussion}

The comparative analysis showed that there are many common health problems among the Balkan countries, but it is also clear that there are significant health inequalities.

Life expectancy is one of the best indicators of country's level of development and of the overall health status of its population. The differences in the level of this indicator are very visible (Fig. 1). The lowest life expectancy is observed in Bulgaria and Serbia, while in Slovenia and Greece LE is 6-7 years higher.

The level of health inequality is best represented when comparing infant mortality and U5MR. Turkey and Albania are the countries with the highest child mortality, where the indicators are 6-7 times higher than Slovenia - the Balkan country that reaches the major developed countries in the world, according to this indicator.

The Healthcare Access and Quality (HAQ) Index provides a summary measure of healthcare access and quality for a given location. This measure is based on risk-standardized mortality rates or mortality-to-incidence ratios from causes that, in the presence of quality healthcare, should not result in death - also known as amenable mortality. The trend of this index in all analysed countries is to 
LIFE EXPECTANCY,2017

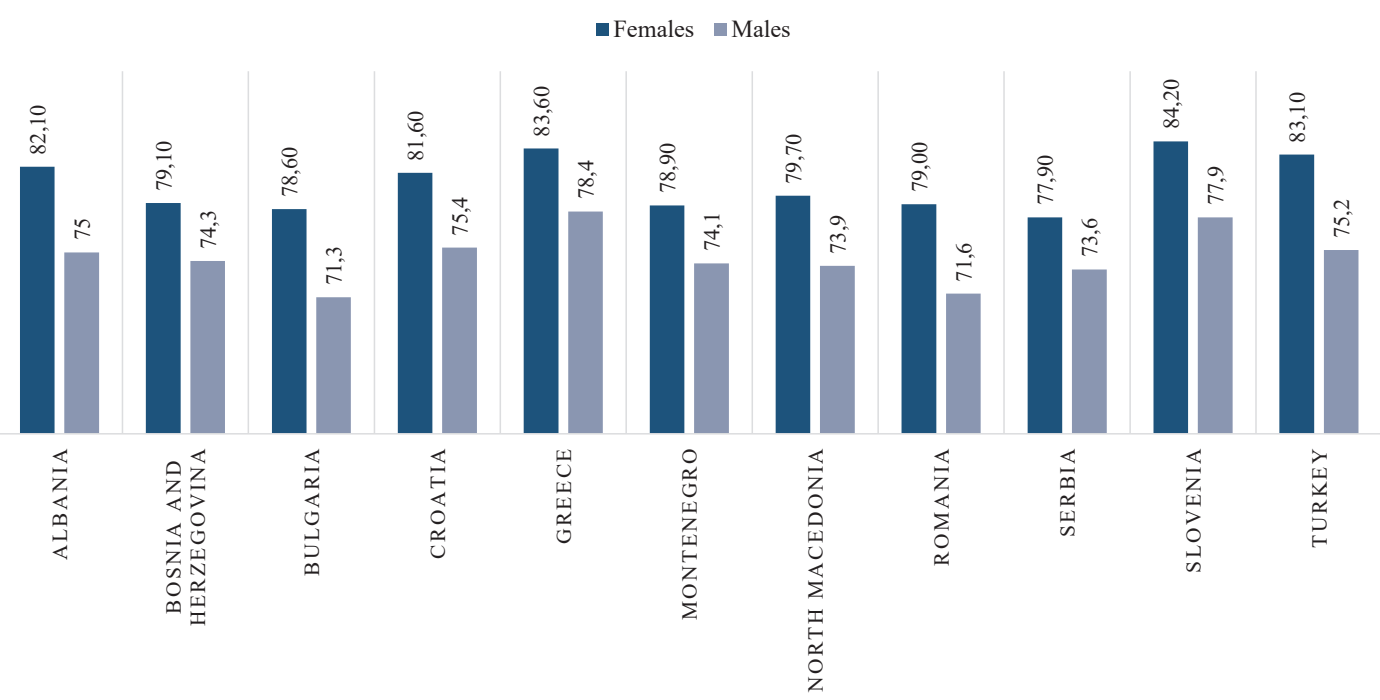

Fig. 1. Life expectancy, 2017.

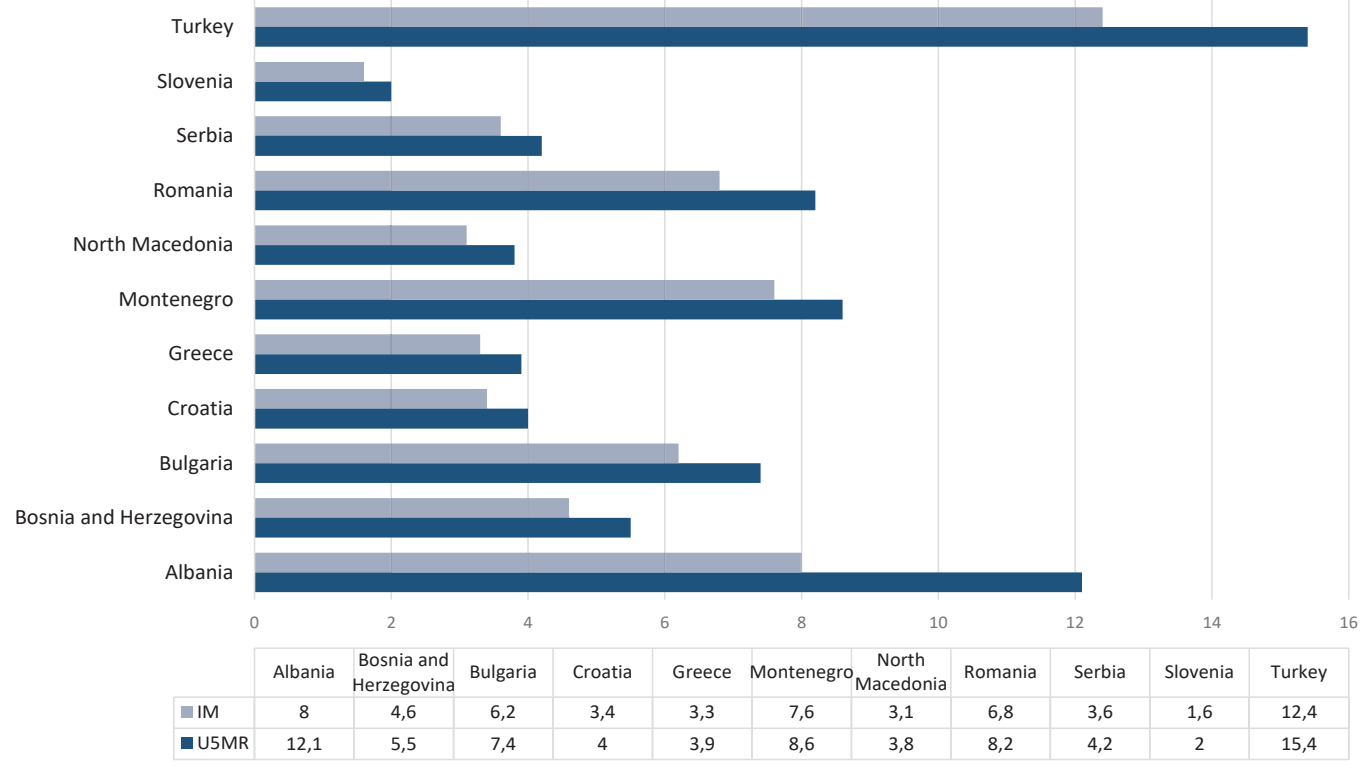

Fig. 2. Child mortality, 2019.

increase for the period 1990-2016, but again Slovenia achieves the highest level with 90.8 and at the bottom is Bosnia and Herzegovina, with 72.2. The average HAQ for the region is 79.9 and only four countries have an index higher than the average - Croatia, Greece, Montenegro and Slovenia (Table 1).

The relationship between Healthcare Access and Quality Index and Health expenditures is presented in Table 2 by Pearson correlation coefficient and supported by two-tailed significance probability. We found a significant positive correlation between HAQ and Health expenditures.

When we analysed the years of life lost to premature death (YLLs), we found out that the leading causes of premature death among Balkan countries are almost the same (Table 3).

The leading cause in all countries is ischemic heart disease, but Bulgaria is the country where this disease causes the highest years of life lost due to premature death. Montenegro has lost the most years due to stroke. The great values of the indicator due to neonatal disorders and congenital defects in Turkey are also impressive.

Table 4 shows that the leading cause for death and disability expressed with DALYs in all Balkan countries is ischemic heart disease. Four countries Slovenia, Croatia, Greece and Montenegro, have significantly lower values of this indicator. 
Table 1. HAQ and Health expenditures by country, 2016, Source: Financing Global Health Database 2019.

\begin{tabular}{ccc}
\hline Country & HAQ & Health expenditures \\
\hline Albania & 75.4 & $\$ 330$ \\
\hline $\begin{array}{c}\text { Bosnia and } \\
\text { Herzegovina }\end{array}$ & 72.2 & $\$ 517$ \\
\hline Bulgaria & 77.2 & $\$ 681$ \\
\hline Croatia & 86.9 & $\$ 939$ \\
\hline Greece & 90.4 & $\$ 1,693$ \\
\hline Montenegro & 81 & $\$ 603$ \\
\hline $\begin{array}{c}\text { North } \\
\text { Macedonia }\end{array}$ & 75.1 & $\$ 364$ \\
\hline Romania & 78.3 & $\$ 537$ \\
\hline Serbia & 77.2 & $\$ 462$ \\
\hline Slovenia & 90.8 & $\$ 2,090$ \\
\hline Turkey & 74.4 & $\$ 445$
\end{tabular}

Table 2. Correlation coefficient for analysed variables.

\begin{tabular}{|c|c|c|c|}
\hline \multicolumn{4}{|c|}{ Correlations } \\
\hline & & VAR00001 & VAR00002 \\
\hline \multirow{3}{*}{ VAR00001 } & Pearson Correlation & 1 &, $904^{* *}$ \\
\hline & Sig. (2-tailed) & &, 000 \\
\hline & $\mathrm{N}$ & 11 & 11 \\
\hline \multirow{3}{*}{ VAR00002 } & Pearson Correlation &, $904^{* *}$ & 1 \\
\hline & Sig. (2-tailed) &, 000 & \\
\hline & $\mathrm{N}$ & 11 & 11 \\
\hline
\end{tabular}

**. Correlation is significant at the 0.01 level (2-tailed).

Table 3. The top causes of premature mortality (YLLs), 2017.

\begin{tabular}{|c|c|c|c|c|c|c|c|}
\hline Country & 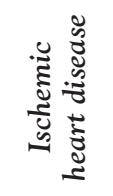 & $\begin{array}{l}\frac{\mathscr{v}}{D} \\
\text { है }\end{array}$ & 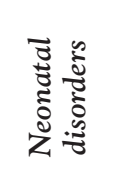 & 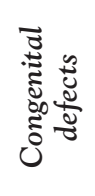 & 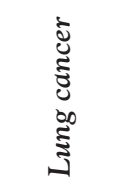 & 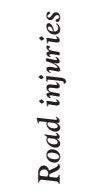 & 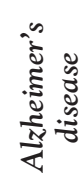 \\
\hline Albania & $2,263.9$ & $1,671.1$ & 948.6 & 624.2 & 535.4 & 389.5 & 326.1 \\
\hline $\begin{array}{c}\text { Bosnia and } \\
\text { Herzegovina }\end{array}$ & $2,359.4$ & $1,720.7$ & 571.4 & 397.4 & 855.6 & 285.5 & 370.7 \\
\hline Bulgaria & $3,604.1$ & $2,126.9$ & 534.5 & 416.4 & 711.5 & 428.0 & 345.5 \\
\hline Croatia & $1,907.6$ & $1,000.5$ & 362.4 & 270.4 & 726.8 & 349.9 & 323.3 \\
\hline Greece & $1,520.4$ & 704.2 & 321.9 & 302.0 & 729.7 & 488.2 & 307.7 \\
\hline Montenegro & $2,393.1$ & $2,591.2$ & 429.1 & 99.1 & $1,039.0$ & 355.1 & 361.8 \\
\hline North Macedonia & $2,185.5$ & $2,334.7$ & $1,004.9$ & 307.6 & 761.5 & 316.8 & 280.2 \\
\hline Romania & $2,624.2$ & $1,865.9$ & 493.6 & - & 753.8 & 449.1 & - \\
\hline Serbia & $2,697.8$ & $2,135.2$ & 526.8 & 207.9 & $1,013.6$ & 313.0 & 387.3 \\
\hline Slovenia & 931.1 & 509.2 & - & - & 618.6 & 292.5 & 260.5 \\
\hline Turkey & $1,730.1$ & 750.6 & $1,283.8$ & 826.6 & 733.1 & 506.5 & - \\
\hline
\end{tabular}

The comparative analysis of GBD 2019 about the risk factors that drive the most death and disability combined shows that Balkan countries have almost the same leading factors - on the first three position are tobacco smoking, high blood pressure, dietary risk or high body-mass index. The biggest problem here is that in two countries profiles - Turkey and Albania - we still see malnutrition as a main risk factor.

\section{Conclusions}

This minireview shows the huge burden of non-communicable diseases in Balkan countries and differences among the countries according to the proportion of DALYs, deaths, and prevalence attributable to the commonest diseases. The analysis of how this burden varies regionally and nationally is important to inform public health policy and prevention strategies.

The prevalence of chronic diseases and burden will likely increase with the progressive ageing of the populations, and health authorities must pay greater attention to the prevention and care of these diseases. The high proportion of DALYs and deaths attributable to chronic diseases can be explained in part by the long life expectancy in Europe and, despite an overall decrease in age-standardised rates, by the increasing incidence and the increasingly long duration of ageing-related diseases. 
Table 4. The top causes of death and disability (DALYs), 2017.

\begin{tabular}{|c|c|c|c|c|c|c|c|c|c|c|}
\hline & 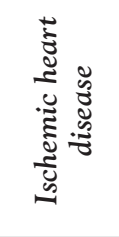 & 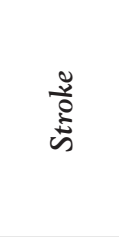 & 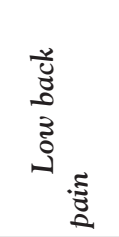 & 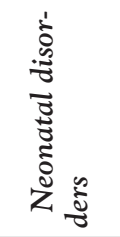 & $\stackrel{\ddot{E}}{\tilde{E}}$ & 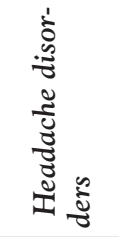 & 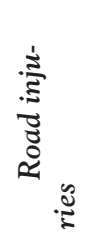 & 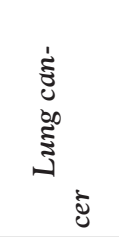 & 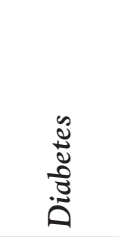 & ఏి \\
\hline Albania & $2,359.6$ & $1,918.1$ & $1,393.9$ & $1,374.5$ & 964.6 & 732.3 & 587.9 & 540.6 & - & - \\
\hline $\begin{array}{l}\text { Bosnia and } \\
\text { Herzegovina }\end{array}$ & $2,472.3$ & $2,041.5$ & $1,142.8$ & $1,062.9$ & 968.1 & 728.4 & - & 863.3 & $1,293.2$ & 606.9 \\
\hline Bulgaria & $3,718.6$ & $2,472.0$ & $1,201.7$ & 973.6 & $1,073.7$ & 730.9 & 645.5 & 718.0 & 649.5 & 636.8 \\
\hline Croatia & $2,018.3$ & $1,274.8$ & $1,374.2$ & 902.1 & 950.9 & 731.8 & 604.2 & 736.2 & 780.5 & 539.6 \\
\hline Greece & $1,585.5$ & 850.5 & $1,288.4$ & 627.8 & - & $1,056.9$ & 653.4 & 738.2 & . & 538.9 \\
\hline Montenegro & $2,515.1$ & $2,881.8$ & $1,320.6$ & 895.5 & 983.1 & 731.3 & 571.0 & $1,048.6$ & 904.8 & - \\
\hline $\begin{array}{c}\text { North } \\
\text { Macedonia }\end{array}$ & $2,284.5$ & $2,660.6$ & $1,177.5$ & $1,484.4$ & 987.2 & 727.6 & 509.4 & 768.1 & $1,015.1$ & 515.5 \\
\hline Romania & $2,733.3$ & $2,210.7$ & $1,346.0$ & 997.4 & $1,155.1$ & 729.0 & 655.5 & 760.5 & . & . \\
\hline Serbia & $2,805.5$ & $2,494.2$ & $1,355.4$ & $1,144.2$ & 995.6 & 730.7 & 505.0 & $1,023.5$ & 955.6 & 680.9 \\
\hline Slovenia & $1,032.2$ & 709.9 & $1,417.5$ & 546.5 & $1,461.0$ & 725.0 & 555.2 & 626.6 & 554.9 & - \\
\hline Turkey & $1,806.8$ & 953.8 & $1,100.7$ & $1,547.5$ & - & 754.4 & - & 740.1 & 889.6 & 955.9 \\
\hline
\end{tabular}

Among Balkan countries, there is a small group of four countries (Slovenia, Croatia, Greece and Montenegro), where socio-economic development and health status of the population are better in comparison with the other countries in Balkan region.

The data suggest different priorities for health service development and resource allocation in different countries. Strategic planning in Balkan countries might use this information to customise plans to efficiently deal with this burden.

\section{Author Contributions:}

Conceptualization, D.K.T.; formal analysis, D.K.T.; methodology, D.K.T.; writing-original draft preparation, D.K.T.

\section{Compliance with Ethics Requirements:}

„The author declares no conflict of interest regarding this article"

„The author declares that all the procedures and experiments of this study respect the ethical standards in the Helsinki Declaration of 1975, as revised in 2008(5), as well as the national law."

"No funding for this study"

\section{Acknowledgements}

None

\section{References}

1. Grancharova G, Kamburova M, Georgieva S, Alexandrova-Yankulovska S, Tsanova D. Dynamics of the causes and risk factors for the global burden of diseases (1990-2015). Social Medicine. 2017; 1: 7-9.

2. Grancharova G, Yankulovska S. Global problems of public health. Publishing Centre MU - Pleven, 2013.

3. The Global Burden of Disease: a critical resource for informed policymaking. Available from: http://www.healthdata.org/gbd/about (accessed on July 18, 2016).

4. Grancharova G, Yankulovska S. Social Medicine, Fifth Edition. Publishing Centre MU - Pleven, 2018.

5. Murray CJ. Quantifying the burden of disease: the technical basis for disability-adjusted life years. Bull World Health Organ. 1994;72: 429-445.

6. Murray C, Salomon J, Mathers C, Lopez A. Summary Measures in Population Health: Concepts, Ethics, Measurement, and Applications. World Health Organization, Geneva; 2002

7. Global Burden of Disease. Generating Evidence, Guiding policy. Institute for Health Metrics and Evaluation, Washington. 2013.

8. Murray CJ, Vos T, Lozano R, et al. Disability-adjusted life years (DALYs) for 291 diseases and injuries in 21 regions, 1990-2010: a systematic analysis for the Global Burden of Disease Study 2010. Lancet. 2012; 380:2197-2223.

9. GBD 2015 Healthcare Access and Quality Collaborators. Electronic address: cjlm@uw.edu; GBD 2015 Healthcare Access and Quality Collaborators. Healthcare Access and Quality Index based on mortality from causes amenable to personal health care in 195 countries and territories, 19902015: a novel analysis from the Global Burden of Disease Study 2015. Lancet. 2017;390(10091):231-266.

10. Global, regional, and national comparative risk assessment of 79 behavioural, environmental and occupational, and metabolic risks or clusters of risks, 1990-2015: a systematic 
analysis for the Global Burden of Disease Study 2015. Lancet 2016;388(10053): P1659-1724.

11. Global, regional, and national disability-adjusted life-years (DALYs) for 315 diseases and injuries and healthy life expectancy (HALE), 1990-2015: a systematic analysis for the Global Burden of Disease Study 2015. Lancet. 2016;388(10053):P1603-1658.

12. Global, regional, and national age-sex-specific mortality for 282 causes of death in 195 countries and territories, 19802017: a systematic analysis for the Global Burden of Disease Study 2017. Lancet 2018;392:1736-88.
13. Global Burden of Disease (GBD), Available from: http:// www.healthdata.org/gbd/2019, (accessed on October 15, 2020).

14. European Commission, State of Health in the EU, Available from: https://ec.europa.eu/health/sites/health/files/state/ docs/chp_bulgaria_bulgarian.pdf (accessed on November 28, 2019).

15. World Economic Situation Prospects, Available from: https://www.un.org/development/desa/dpad/wp-content/ uploads/sites/45/WESP2020_ Annex.pdf (accessed on January 16, 2020). 